\title{
Ocorrência de sirfídeos afidófagos (Diptera, Syrphidae) em Lavras, MG
}

\author{
Alexander Machado Auad ${ }^{1} \&$ Raphael Trevizani²
}

'Lab. de Entomologia, EMBRAPA-CNPGL, R. Eugênio Nascimento, 610, 36038-330 Juiz de Fora-MG, amauad@cnpgl.embrapa.br ${ }^{2}$ Univ. Federal de Juiz de Fora, Campus Universitário, 36036-330 Juiz de Fora-MG. raphaeltrevizani@yahoo.com.br

\begin{abstract}
Occurrence of aphidophagous syrphids (Diptera, Syrphidae) in Lavras, MG. The occurrence of aphidophagous syrphids was studied on citrus, cabbage, cucumber, wheat and potato crops. Samplings were done every 15 days from August to December 2002. The species recorded were: Ocyptamus gastrostactus (Wiedemann, 1830), Allograpta exotica (Wiedemann, 1830), Pseudodorus clavatus (Fabricius, 1794) and Ocyptamus anthiphates (Walker, 1849). P. clavatus occurred on all the crops and showed the highest population density (72\%). It was followed by $O$. gastrostactus $(16 \%)$, A. exotica $(11 \%)$ and $O$. anthiphates $(1 \%)$. The occurrence of the syrphids was correlated with the weather conditions and the presence of aphids.
\end{abstract}

KEYWORDS. Insecta, predator, survey, syrphids.

RESUMO. Ocorrência de sirfídeos afidófagos (Diptera, Syrphidae) em Lavras, MG. A ocorrência de sirfídeos afidófagos nas culturas de citros, couve, pepino, trigo e batata foi registrada. As amostragens foram realizadas, quinzenalmente, de agosto a dezembro de 2002. Constatou-se as espécies: Ocyptamus gastrostactus (Wiedemann, 1830), Allograpta exotica (Wiedemann, 1830), Pseudodorus clavatus (Fabricius, 1794) e Ocyptamus anthiphates (Walker, 1849). P. clavatus ocorreu em todas as culturas amostradas, com a maior densidade populacional (72\%), seguido de O. gastrostactus (16\%), A. exotica $(11 \%)$ e $O$. anthiphates $(1 \%)$. A ocorrência dos sirfídeos esteve correlacionada com os fatores climáticos e a presença dos afídeos.

PALAVRAS-CHAVE. Insecta, predadores, levantamento, sirfídeos.

A presença de espécies e a densidade populacional de sirfídeos afidófagos são determinados por fatores climáticos, disponibilidade de flores e presas, habitat e área geográfica.

No Brasil a ocorrência de espécies comumente associadas aos afídeos em diferentes culturas foi registrada por Silva et al. (1968), Gonçalves \& Gonçalves (1976), Bartoszeck (1976), Leal et al. (1976), Lazzari (1985), Gassen (1986), Auad et al. (1997) e Mendes et al. (2000).

Auad et al. (1997) constataram um sincronismo entre a presença dos sirfídeos Allograpta neotropica (Curran, 1936), Ocyptamus gastrostactus (Wiedemann, 1830), Syrphus phaetostigma (Wiedemann, 1830), Ocyptamus dimidiatus (Fabricius, 1781) e Pseudodorus clavatus (Fabricius, 1794) e o afídeo Brachycaudus schwartzi (Börner, 1931). Correlação positiva entre a população desses predadores com afídeos da alfafa (Therioaphis trifolii (Monel, 1882), Acyrthosiphon pisum (Harris, 1776), Acyrthosiphon kondoi Shinji, 1938 e Aphis craccivora (Kock, 1854) também foi relatada por Mendes et al. (2000).

O objetivo do presente trabalho foi avaliar a ocorrência das espécies de sirfídeos afidófagos, em Lavras, MG, contribuindo assim com informações sobre a bioecologia dos sirfídeos em culturas, nas quais os afídeos estão presentes.

Quinzenalmente, de agosto a dezembro/2002, larvas de sirfídeos foram amostradas em cultivos de citros, couve, pepino, trigo e batata. Essas foram retiradas com auxílio de um pincel, colocadas em tubos de fundo chato com $8,5 \mathrm{~cm}$ de altura x 2,5 cm de diâmetro, levadas para o laboratório de
Entomologia da Universidade Federal de Lavras e mantidas à temperatura de $25 \pm 1{ }^{\circ} \mathrm{C}$, umidade relativa de $70 \pm 10 \%$, fotoperíodo de 12 horas. Ninfas do afídeo Schizaphis graminum (Rondani, 1852) foram ofertadas ad libitum para larvas do predador, até alcançarem o estágio de pupa. Adultos foram armazenados em álcool a $70 \%$ e identificado por Christian Thompson (Departament of Entomology, Smithsonian Institute, Washington).

A temperatura média $\left({ }^{\circ} \mathrm{C}\right)$, umidade relativa média $(\%)$ e precipitação $(\mathrm{mm})$ foram obtidos durante todo o período de estudo na Estação Agroclimatológica, distante a aproximadamente $100 \mathrm{~m}$ das culturas avaliadas. A influência dos fatores climáticos sobre a ocorrência dos sirfídeos foi avaliada por correlação entre o número total de cada espécie do predador obtida em cada amostragem e a média da temperatura, umidade relativa e precipitação registrada nos quinze dias anteriores à data da amostragem. Uma análise de correlação entre as espécies de sirfídeos e a presença de afídeos também foi efetuada.

Larvas e adultos de sirfídeos foram fotografados e as espécies de ocorrência foram registradas, servindo a futuros estudos sobre a viabilidade desses como agentes no controle biológico de afídeos praga.

Constatou-se a ocorrência dos sirfídeos: $O$. gastrostactus, Allograpta exotica (Wiedemann, 1830), P. clavatus e Ocyptamus anthiphates (Walker, 1849) (Figura 1), estando a presença destes predadores correlacionada positivamente com a dos afídeos das plantas amostradas. Os resultados 

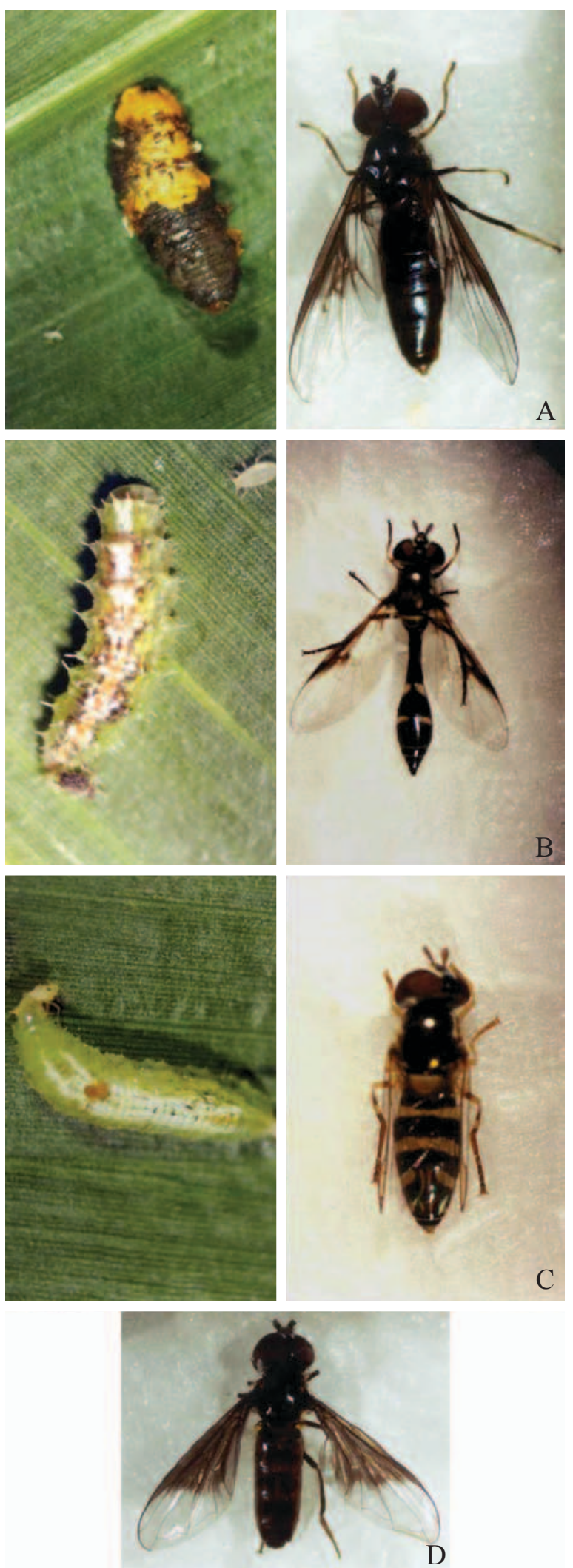

Fig. 1. Larvas e adultos de Ocyptamus gastrostactus(A), Pseudodorus clavatus (B), Allograpta exotica (C) e adulto de Ocyptamus anthiphates (D).

Recedido em 04.VIII.2004; aceito em 07.II.2005 concordam com os obtidos por Auad et al. (1997), que registraram as maiores densidades populacionais de sirfídeos afidófagos quando $B$. schwartzi atingiu o seu pico populacional e com Bartoszeck (1976) que somente encontrou larvas de sirfídeos quando a população de $B$. schwartzi encontrava-se alta. Mendes et al. (2000) também evidenciaram correlação positiva entre a população desses predadores com os afídeos da alfafa, em Lavras, MG.

A espécie $P$. clavatus ocorreu em todas as culturas estudadas, sendo aquela com maior densidade populacional (72\%), seguida de O. gastrostactus (16\%) associada a Toxoptera citricicola (Kirkaldy, 1907) e Brevicoryne brassicae (Linnaeus, 1758), A. exotica (11\%) a Aphis gossypi Glover, 1877, Myzus persicae (Sulzer, 1776) e B. brassicae, e $O$. anthiphates (1\%) que esteve associada a $M$. persicae.

O número total de sirfídeos amostrados foi correlacionado positivamente com a temperatura e negativamente com a umidade relativa. Constatação semelhante foi feita por Auad et al. (1997), no estudo desses predadores associados a $B$. schwartzi. As maiores densidades populacionais foram registradas na segunda quinzena de agosto e outubro e na primeira de novembro, quando a temperatura era superior a 20 ${ }^{\circ} \mathrm{C}$. Mendes et al. (2000) verificaram o pico populacional dos sirfídeos no mês de abril com temperatura em torno de $20^{\circ} \mathrm{C}$, em Lavras, MG.

As figuras 1A e 1B mostram uma diferença nítida na coloração e aspectos gerais das larvas e adultos de $O$. grastrostactus e $P$. clavatus, que são geralmente ilustradas erroneamente nos textos de entomologia, como sendo todas de $P$. clavatus.

\section{REFERÊNCIAS}

Auad, A. M.; V. H. P. Bueno; C. M. Kato \& D. C. Gamarra. 1997 Ocorrência e flutuação populacional de predadores e parasitóides de Brachycaudus (Appelia) schwartzi (Börner) (Homoptera: Aphididae), em pessegueiro, em Jacuí-MG. Anais da Sociedade Entomológica do Brasil 26: 257-263.

Bartoszeck, A. B. 1976. Afídeos da ameixeira (Prunus domestica L.) e pessegueiro (Prunus persicae Sto.), seus predadores e parasitas. Acta biológica Paranaense 5: 69-91.

Gassen, D. N. 1986. Parasitas, patógenos e predadores de insetos associados à cultura do trigo. Embrapa CNT, 86 p. Passo Fundo (circular técnica, 1).

Gonçalves, C. R. \& A. J. L. Gonçalves. 1976. Observações sobres moscas da família Syrphidae predadoras de homópteros. Anais da Sociedade Entomológica do Brasil 5: 3-10.

Lazzari, S. N. 1985. Inimigos naturais dos afídeos (Homoptera, Aphididae) da cevada (Hordeum sp.) no Paraná. Anais da Sociedade Entomológica do Brasil 14: 5-15.

Leal, C. A.; H. C. C. Oliveira \& J. G. Smith. 1976. Syrphidae predadores dos afídeos de Citrus spp. em Recife, PE. Anais da Sociedade Entomológica do Brasil 5: 138-142.

Mendes, S.; M. N. Cerviño; V. H. P. Bueno \& A. M. Auad. 2000. Diversidade de pulgões e de seus parasitóides e predadores na cultura da alfafa. Pesquisa Agropecuária Brasileira 35: 1305-1310.

Silva, A. G. A.; C. R. Gonçalves; D. M. Galvão; A. J. L. Gonçalves; J. Gomes; M. N. Silva \& L. Simoni. 1968. Quarto catálogo dos insetos que vivem nas plantas do Brasil: seus parasitos e predadores. Rio de Janeiro, 1:622p. 